\title{
Subsidiária de TI como alternativa estratégica para economia dos custos de transação: estudo de caso em um grupo financeiro multinacional
}

\section{RESUMO}

Este artigo tem por objetivo analisar como uma subsidiária de Tecnologia da Informação (TI) pode contribuir para a economia dos custos de transação de um grupo financeiro multinacional. Para melhor compreender essa relação e identificar se há ou não economia nos custos de transação, foi feito um estudo de caso com a intenção de buscar evidências das cinco dimensões da teoria dos custos de transação: oportunismo, racionalidade limitada, incerteza, especificidade de ativos e frequência da transação. Os dados utilizados para a pesquisa foram obtidos por meio de pesquisa bibliográfica e documental, e entrevistas com funcionários das duas empresas de um grupo financeiro multinacional. Os resultados demonstram que a capacidade de centralização das informações, com o intuito de desenvolver competências para inovar ou para a customização dos serviços prestados pela empresa mãe, foi um dos fatores que motivaram a manutenção de uma estrutura própria de Tl. Além disso, em virtude dos pressupostos comportamentais, das características das transações e dos ativos envolvidos, manter a estrutura de TI integrada na dimensão hierárquica, na forma de uma subsidiária, pode garantir à organização principal economia nos custos de transação. Os resultados deste estudo ratificam os princípios sobre a Teoria dos Custos de Transação.

Palavras-chave: Grupo financeiro. Subsidiária de TI. Economia dos custos de transação.

Thálita Anny Estefanuto Orsiolli thalitanny@gmail.com Doutoranda em Administração pela Universidade Federal do Paraná

Rodrigo Luiz Morais-da-Silva rlm_slv@hotmail.com Doutorando em Administração pela Universidade Federal do Paraná 


\section{INTRODUÇÃO}

O uso de tecnologias proporciona o desenvolvimento de novas estruturas organizacionais, na medida em que a Tecnologia da Informação (TI) assume uma estratégia de negócios relacionada às diretrizes e formas de relacionamento e operacionalização das atividades do ambiente em que atua. Assim, a TI relaciona-se às ações internas (qualidade, flexibilidade, inovação) e externas da empresa (pressões do mercado, competitividade) a fim de associar as oportunidades de negócios advindas do ambiente externo às estratégias de TI da organização (ALBERTIN; ALBERTIN, 2005; LUCAS, 2006; PEARLSON; SAUNDERS, 2010).

A Tl é utilizada pelas empresas como um recurso crítico para o processamento e acesso a informações, uma vez que contribui para a junção, armazenamento e aplicação do conhecimento na criação de novas relações de parceria entre cliente-fornecedor, novos procedimentos, resolução de problemas, entre outros aspectos (LUCAS, 2006; PEARLSON; SAUNDERS, 2010).

Nesse contexto, o ambiente organizacional tornou-se mais complexo, de modo que a demanda por serviços de TI passa a ser considerada a base para atender às novas necessidades das organizações. Dessa forma, uma relação intrínseca entre a Tl e as atividades organizacionais é estabelecida, pois as pressões ambientais requerem novas tecnologias (software, hardware e redes) em um ambiente heterogêneo. Essa heterogeneidade faz com que as organizações busquem novas alternativas para obter vantagem competitiva diante dos competidores. Com isso, é possível entender que o direcionamento estratégico inicia-se com a decisão de fazer ou comprar serviços de tecnologia da informação (CORDENONSI, 2005; PEARLSON; SAUNDERS, 2010).

Em mercados globalizados, as instituições financeiras destacam-se como organizações que se utilizam primordialmente da troca de informações para estabelecer processos e coordenar os negócios, de maneira que se faz necessário organizar, gerir e conduzir essas informações por meio da essência da estratégia e eficiência da TI. Assim, as empresas de serviços financeiros organizam seu processo de produção como qualquer outra empresa, decidindo quais produtos/serviços de TI serão produzidos e quais serão comprados externamente (RODRIGUES; MACCARI; SIMÕES, 2009; PEARLSON; SAUNDERS, 2010; CLARK; MONK, 2013).

Assim sendo, é possível compreender que alinhar as estratégias de TI com a forma de negócio relacionase ao modo como as empresas organizam suas transações, ou seja, se elas buscam seus bens no mercado ou se a escolha pauta-se em produzir internamente. Logo, os custos de transação inserem-se na escolha da estrutura organizacional que mais se encaixa para a redução dos custos (PEARLSON; SAUNDERS, 2010; MESQUITA et al., 2013).

Diante da dubiedade entre buscar no mercado serviços de TI ou manter uma estrutura interna de apoio, o presente artigo procurou investigar a estrutura de TI de um grupo multinacional, que optou por manter uma estrutura física própria para o desenvolvimento de atividades de tecnologia da informação. Portanto, este artigo possui como objetivo principal analisar de que forma uma subsidiária de TI pode contribuir para a economia dos custos de transação de um grupo financeiro multinacional. A intenção foi relacionar as cinco categorias da Teoria dos Custos de Transação (TCT): racionalidade limitada, oportunismo, incerteza, frequência da transação e especificidade de ativos, com as evidências obtidas no caso investigado.

Para que o objetivo deste estudo fosse concluído, o artigo foi estruturado em seis seções: a primeira delas é esta introdução; a segunda seção apresenta o referencial teórico referente às estratégias de TI e a TCT; a terceira aborda os procedimentos metodológicos utilizados; a quarta seção apresenta o caso ao leitor; já, na quinta seção, é apresentada a análise dos dados coletados. A última seção, por sua vez, é responsável por externar as considerações principais deste estudo e suas conclusões fundamentais.

\section{REFERENCIAL TEÓRICO}

Diante do objetivo proposto neste artigo, faz-se necessária a abordagem de dois campos de estudo. Por isso, o referencial teórico é subdivido em duas partes: a primeira é responsável por evidenciar a literatura sobre as estratégias de tecnologia da informação, e a segunda discute os principais conceitos da Teoria dos Custos de Transação. 


\subsection{Estratégias de Tecnologia da Informação}

Esta seção tem por finalidade demonstrar a definição e utilização das diferentes estratégias de Tl, bem como relacionar essa escolha à estratégia de negócio.

Pearlson e Saunders (2010) ressaltam que a estratégia de negócio constitui um plano traçado pela empresa em resposta às forças do mercado (concorrência), à demanda dos clientes (desejos e necessidades dos indivíduos) e às suas capacidades organizacionais (habilidades e experiências), a fim de estabelecer ou mesmo comunicar seus objetivos. As autoras também explicam que a estratégia de Sistema de Informação é utilizada para dar suporte aos objetivos de forma a complementar a estratégia de negócios da organização, por meio do fornecimento de serviços de informação.

Diante da importância de gerenciar a informação, pode-se inferir que a TI vem sendo incorporada à estrutura interna organizacional, renunciando à orientação de suporte administrativo e assumindo uma estratégia de negócios. Com isso, Laurindo et al. (2001, p. 176) explicam que a gestão de Tl, desde sua estratégia até seu planejamento, deve ser um processo contínuo e flexível, a fim de acompanhar as mudanças externas com a intenção de obter "novas possibilidades de estratégias de negócio e disponibilidades de TI".

Em empresas como as de serviços financeiros, cujo principal produto é centrado na informação, a forma como essa informação é organizada, gerida e conduzida determina a essência da estratégia e a eficiência da TI (RODRIGUES; MACCARI; SIMÕES, 2009; PEARLSON; SAUNDERS, 2010).

Sendo assim, é possível entender que o direcionamento estratégico inicia-se com a decisão de comprar (terceirizar) ou fazer (internamente) serviços e produtos de informação ou, como é chamado na literatura, estratégias de outsourcing, offshoring e insourcing, as quais serão detalhadas a seguir.

\subsubsection{Estratégias de Terceirização de TI}

As estratégias de terceirização ou outsourcing compreendem a vontade de determinada empresa "não desejar mais utilizar seus recursos internos para operar ou implementar sua área de $\mathrm{TI}$, e vir a contratar uma organização externa para fornecer esse serviço" (SILVA et al., 2009, p. 176) .

Um dos fatores mais comuns para a terceirização de atividades de TI relaciona-se a redução de custos, uma vez que o processo de desenvolvimento e controle da infraestrutura de TI é oneroso e demanda tempo, profissionais especializados e investimento constante. A opção pelo outsourcing igualmente pode ser vista como a possibilidade de a empresa adquirir a transição para novas tecnologias, serviços e profissionais especializados, possuir amplitude de controle sobre o centro de dados ou mesmo uma forma estratégica de concentrar as atividades em um provedor de TI (SILVA et al., 2009; PEARLSON; SAUNDERS, 2010).

O outsourcing também exige alguns desafios para a empresa, tais como entregar determinado grau de controle sobre aspectos críticos da empresa; restringir-se a adquirir novas tecnologias em virtude de questões de contrato; tornar as informações confidenciais passíveis de acesso por meio do fornecedor de terceirização, entre outros. Para tanto, é importante que a organização defina suas estratégias de TI para direcionar a forma de gestão de acordo com os propósitos pretendidos (PEARLSON; SAUNDERS, 2010).

Outra maneira de gerir produtos e/ou serviços de Tl é realizada por meio de offshoring, que é considerado um outsourcing fora do local de origem (país) da empresa contratante desse serviço. Ou seja, quando a gestão da informação utiliza serviços contratados, ou mesmo constrói seu próprio centro de dados em uma terra distante pelos mais diversos motivos, questões de custos com tecnologia e mão de obra, ou mesmo gerenciamento estratégico (PEARLSON; SAUNDERS, 2010).

Estudos como o de Prado e Takaoka (2002) identificaram sete fatores que motivam as organizações a terceirizar seus setores de TI: redução dos custos, acesso ao conhecimento de $\mathrm{Tl}$, gestão de recursos humanos, atividades rotineiras, prestação de serviços, flutuação na carga de trabalho e atividades com alto grau de particularidades. A seguir, apresenta-se uma descrição dos fatores observados no estudo de Prado e Takaoka (2002).

Fator 1: A principal motivação para a opção pela estratégia de terceirização de TI foi a redução de custos alcançada. 
Fator 2: Em seguida, o acesso ao conhecimento e à TI mostrou-se uma importante explicação para a terceirização, principalmente para empresas de pequeno porte que não tinham acesso à TI desenvolvida dentro da organização.

Fator 3: A gestão de recursos humanos foi a terceira justificativa apresentada pelas empresas analisadas e foi levantada principalmente por empresas de pequeno porte, que não possuem recursos humanos capazes de operar ou gerenciar um setor de TI.

Fator 4: A quarta razão para terceirização se deu em setores de TI que trabalham de forma mais autônoma e, então, puderam optar por terceirizar as atividades rotineiras e mais simples.

Fator 5: Em empresas de médio e grande porte, a prestação de serviços específicos, como os de desenvolvimento de software, foram aqueles repassados para outras empresas prestadoras do serviço.

Fator 6: A flutuação na carga de trabalho foi o sexto motivo para a terceirização, pois empresas de portes menores possuem demandas de TI em menor intensidade, facilitando assim a terceirização.

Fator 7: O sétimo fator motivador foi observado em atividades com alto grau de particularidade e que não poderiam ser desenvolvidas internamente.

Com base no estudo de Prado e Takaoka (2002), é possível notar que a opção das empresas por terceirizar um setor de TI pode estar relacionada não apenas à redução de custos, mas também à qualidade dos serviços, assim como ao direcionamento estratégico pretendido pela empresa, a qual poderá enfatizar a busca por profissionais especializados para suprir tal demanda.

\subsubsection{Estratégias de Manutenção da TI Interna}

Pearlson e Saunders (2010) argumentam que o insourcing (TI interna) é considerado a abordagem tradicional para o fornecimento e gestão dos serviços de TI, uma vez que a própria organização oferece e desenvolve tais serviços. Essa prática igualmente é utilizada com a finalidade de manter as competências essenciais e mesmo a confidencialidade de um produto ou serviço. Além da TI totalmente integrada à estrutura da organização principal, há outras formas de organizações, ainda sob o controle da empresa principal, como as empresas subsidiárias, um dos objetos de estudo deste artigo.

As empresas subsidiárias se estabelecem como outra forma de estratégia, a qual se pauta em uma subdivisão ou instituição de uma empresa por outra já consolidada no mercado, como meio de diversificar ou ampliar suas operações no mercado global. Esse modelo permite que as matrizes (empresas mãe) maximizem sua vantagem competitiva por centralizar funções específicas em suas filiais, para com isso abranger novos mercados, e também admite que a subsidiária reconheça e domine novos cenários, com a finalidade de aumentar sua capacidade de conhecimento ou mesmo de negociação, perante o surgimento de novas oportunidades (TAGGART, 1997).

No caso da Tl, a subsidiária possibilita o fornecimento e gestão dos produtos ou serviços de $\mathrm{TI}$. A escolha por essa estratégia pode estar relacionada à capacidade de centralizar as informações (recursos) com o intuito de compreender e desenvolver as competências necessárias para inovar, ou mesmo aumentar a dimensão do negócio realizado, assim como, pode servir para abranger novas parcerias diante do mercado local e global (BIRKINSHAW; MORRISON, 1995; BIRKINSHAW; HOOD, 1998).

Essa estratégia de TI também pode utilizar-se das possibilidades obtidas por offshoring, dado que muitas empresas subsidiárias se estabelecem fora do seu país a fim de ampliar sua relevância estratégica, gerar vantagem competitiva, ou ainda abranger novos cenários com o propósito de tornarem-se centros de excelência (SILVA et al., 2009).

Nesse sentido, a opção por uma empresa subsidiária de TI não apenas dependerá do papel a ser desempenhado por ela, como da escolha estratégica definida pela empresa mãe, de modo que atuar de forma autônoma com relação à matriz, ou mesmo estabelecer-se como uma subsidiária integral, na qual os processos de negócios são integrados e sincronizados pelas empresas controladoras, relaciona-se aos objetivos da empresa matriz (LUO, 2005; SCUMPARIM; SACOMANO NETO, 2012).

Diante das estratégias de TI apresentadas, percebe-se que gerenciar a informação assumida como função estratégica em um negócio está relacionado ao modo como referida informação é conduzida, o que 
determinará a eficiência do setor de TI de uma organização. Dessa forma, decidir e alinhar a estratégia de TI que melhor se adapta à realidade e ao posicionamento estratégico do negócio não apenas incide na maneira como as empresas gerenciam suas transações, como interferem nos custos relacionados a tais transações. Assim, na próxima seção, será apresentada a Teoria dos Custos de Transação, com o propósito de procurar compreender como os custos de transação podem interferir na escolha da estratégia de TI.

\subsection{Teoria dos Custos de Transação}

Os estudos acerca da TCT iniciaram-se a partir do artigo seminal de Coase (1937). Nele, o autor expõe suas considerações a respeito da importância das firmas e da produção interna ao compará-las com a compra direta do mercado. No entendimento do autor, quando se compra algo diretamente no mercado, não se deve considerar apenas o valor de compra do produto, mas a esse valor devem ser acrescidos custos, como aqueles necessários para a pesquisa que o comprador deverá proceder e os custos para a negociação com o vendedor. Portanto, os custos de transação devem ser somados aos custos de mercado de um produto.

Após a iniciação aos estudos sobre TCT com Coase (1937), Oliver E. Williamson foi o autor proeminente dessa abordagem teórica. Porém, antes de tratar especificamente dos custos de transação, é necessário conhecer o conceito de transação que, de acordo com Williamson (1981, p. 552), "ocorre quando um bem ou um serviço é transferido através de uma interface tecnologicamente separável". Com base no planejamento ou na realização dessas transações, podem incorrer os então chamados custos de transação, que são identificados quando a organização decide por recorrer ao mercado e não produzir internamente aquilo que precisa (COASE, 1937).

Os custos de transação, no entendimento de Williamson (1981), podem acontecer em dois momentos: exante, como a negociação, e ex-post, como o monitoramento de execução de contratos. Dessa maneira, o autor sugere que as organizações devem considerar os custos envolvidos antes e após as transações, e tentar minimizálos, pois "a economia é a melhor estratégia" (WILLIAMSON, 1991, p. 76). Diante da importância dos custos de transação para o desempenho das organizações, a próxima seção tratará das cinco dimensões inerentes à TCT.

\subsubsection{Dimensões da TCT}

Os custos de transação são influenciados por dois fatores principais: os comportamentais e os relacionados às características das transações (WILLIAMSON, 1979; CARSON; MADHOK; WU, 2006; SILVA; BRITO, 2013), conforme descritos a seguir.

a) Pressupostos comportamentais

Os pressupostos comportamentais da TCT são a racionalidade limitada e o comportamento oportunista. Williamson (1975), embasado nos argumentos de Simon (1965), indica que racionalidade limitada é um dos fatores comportamentais que exercem influências nas transações e nos custos dessas transações. Simon (1965) assegura que a decisão ótima não pode ser alcançada pelo ser humano, pois sua capacidade de raciocínio é limitada, pois que ele não possui acesso a todas as informações necessárias e não consegue prever com exatidão as consequências de suas ações. Diante dessas características intrínsecas ao ser humano, ele é capaz apenas de tomar decisões satisfatórias. De acordo com Dequech (2001), a expressão "racionalidade limitada" pode ser igualmente utilizada para demonstrar pessoas ou organizações imersas em ambientes complexos, quando comparados às suas capacidades e habilidades mentais.

Além da racionalidade limitada, no percurso de uma transação, o oportunismo torna-se uma influência às relações, pois, conforme Williamson (1985, p. 47), "os agentes econômicos buscam os seus próprios interesses nas transações, agem em benefício próprio aproveitando-se de lacunas ou omissões contratuais em detrimento dos parceiros". Desse modo, qualquer brecha que exista em um contrato pode ser campo para a atuação oportunista dos agentes.

b) Características das transações

Além dos fatores comportamentais, as características das transações também influenciam nos custos de transação, sendo as principais: incerteza, frequência e especificidade de ativos. A respeito da incerteza, de acordo com Silva e Brito (2013, p. 183), "em linhas gerais, a incerteza na teoria das organizações tem sido 
entendida como o grau de imprevisibilidade das mudanças e do grau de dissimilaridade dos seus elementos". Pode-se considerar que a incerteza e a racionalidade limitada possuem relações estreitas, pois na medida em que o ser humano é dotado de racionalidade limitada, ele não possui domínio sobre todas as variáveis (SIMON, 1965), caracterizando, então, decisões tomadas em ambientes tocados pelas incertezas (WILLIAMSON, 1985).

Além da incerteza, outro aspecto importante no contexto da teoria dos custos de transação é a frequência com que ela ocorre. Quanto maior for a frequência da transação, maiores são as possibilidades de aumento dos custos de transação. Por isso, é necessário o desenvolvimento de um contrato mais específico; no entanto, cabe ressaltar que eles não conseguem ser totalmente abrangentes e completos (WILLIAMSON, 1985). Diante dessa conclusão, pode-se dizer que transações mais frequentes caminham para uma forma de governança hierárquica ou híbrida, como será explicado na sequência deste artigo.

Por fim, um dos elementos que exerce maior influência nos custos de transação é a especificidade de ativos, que é evidenciado por investimentos feitos que não são facilmente transportados para outros usos (WILLIANSON, 1991). Dessa maneira, o relacionamento específico com outras organizações na tentativa de obter ativos específicos ou os investimentos para a produção interna desse ativo são fontes de custos de transação (SILVA; BRITO, 2013).

Williamson (1985) identifica quatro fontes de especificidade de ativos no que se refere aos seus aspectos de localização, físicos, de capital humano e ativos dedicados, apresentados a seguir: (i) especificidade de localização: alguns ativos específicos são desenvolvidos para atividades em determinada localização e dificilmente podem ser alocados para outros locais e fins; (ii) especificidade física: há negócios que necessitam de ativos altamente customizados para a adequação à sua finalidade; sendo assim, dificilmente poderiam ser utilizados em outros negócios ou para outros fins; (iii) especificidade de capital humano: alguns produtos ou serviços são de tamanha peculiaridade que não há mão de obra específica no mercado para aquela atividade. Por isso, a equipe de produção aprende pela experiência e, com isso, torna-se difícil encontrar capital humano disposto e apto para exercer tal atividade; (iv) especificidade de ativos dedicados: alguns investimentos em ativos são feitos exclusivamente pela expectativa de venda de grande quantidade para um determinado fim. Caso não existisse essa finalidade específica, dificilmente esse investimento teria ocorrido.

A frequência das transações, a especificidade de ativos e a incerteza são características inerentes às transações, cujas variações podem dar suporte ao surgimento de ações oportunistas, tangenciadas pela racionalidade limitada (CARSON; MADHOK; WU, 2006), que culminam no aumento dos custos de transação.

Além da racionalidade limitada, oportunismo, incerteza, frequência e especificidade, elementos principais da TCT, faz-se importante abordar as estruturas de governança, evidenciadas na sequência.

\subsubsection{Estrutura de Governança}

De acordo com Williamson (1979), são encontradas basicamente três estruturas de governança: a de mercado, a híbrida e a governança hierárquica, as quais são descritas a seguir.

A governança de mercado é também conhecida como a forma de contratação clássica em que uma organização vai ao mercado comprar produtos ou serviços de que necessita no seu processo. Essa estrutura de governança é indicada para transações que envolvam principalmente ativos não específicos, ou seja, produtos e serviços padronizados que são requeridos de forma recorrente ou não. As transações ocasionais estão mais sujeitas a ações oportunistas quando comparadas às transações recorrentes, pois não existem relações estreitas entre compradores e vendedores (WILLIAMSON, 1979).

Já a governança híbrida é estratégia de governança indicada para transações não recorrentes e com o envolvimento de ativos altamente específicos que são difíceis para se encontrar no mercado e caros para a produção interna. Então, desenvolve-se uma forma de governança com características que se localizam entre os dois opostos da integração vertical e da compra no mercado. Nessa estratégia de governança, há um contrato entre as partes e grande interesse de ambas pelo seu cumprimento (WILLIAMSON, 1979).

A terceira configuração de governança é a hierárquica. É indicada para ativos com alta especificidade e recorrência, pois características de produtos ou serviços altamente específicos aumentam o risco e o custo da compra nas estruturas de mercado; já a recorrência das transações garante que o investimento realizado na gestão seja recuperado (WILLIAMSON, 1979). 
A respeito das escolhas entre as formas de governança, quando as transações ocorrem em situações esporádicas, o produto envolvido não representa um alto grau de especificidade de ativos, e os agentes de mercado sentem-se motivados para o desenvolvimento do produto, a governança de mercado torna-se uma estratégia eficiente na medida em que os produtos são adquiridos no mercado por um preço menor e com maior qualidade. Nesse sentido, quando os produtos ou serviços envolvidos são de alta especificidade, repletos de incertezas e sua necessidade seja recorrente, a forma contratual ou a hierárquica são as mais indicadas, pois podem reduzir os possíveis custos de transação na medida em que as duas últimas auxiliam na redução do oportunismo e da racionalidade limitada inerente nas relações entre compradores e vendedores (WILLIAMSON, 1991).

\section{PROCEDIMENTOS METODOLÓGICOS}

Para a realização do objetivo de analisar como a estratégia de uma empresa subsidiária de TI pode contribuir para a economia dos custos de transação de um grupo multinacional, foi utilizada uma abordagem qualitativa de cunho exploratório, uma vez que se buscou entender, interpretar e mesmo se relacionar com o fenômeno, a fim de se obter mais informações sobre o objeto em análise (CERVO; BERVIAN, 2002; DENZIN; LINCOLN, 2006).

Sendo assim, realizou-se um estudo de caso com o objetivo de buscar entender as interações complexas (YIN, 2005) entre a opção por determinada estratégia e as vantagens relacionadas a custo para a empresa mãe. A justificativa pela escolha do caso único deu-se pela sua raridade e relevância da organização que, conforme dados da Brand Finance (2015), é um dos grupos financeiros com maior valor de marca no mundo. Seus serviços estão disponíveis em países da Europa, Ásia, Oriente Médio, América do Norte e América Latina. Além disso, a escolha do caso deu-se por sua estratégia de utilização de serviços de TI internos, enquanto outras empresas de grande porte optam, em geral, pela terceirização desses serviços, em especial pela diminuição dos custos diretamente relacionados (SILVA et al., 2009; PEARLSON; SAUNDERS, 2010).

Por se tratar de uma organização de grande complexidade internacional, e por envolver vários coeficientes de horários e integração, a comunicação entre subsidiárias só é possível caso haja uma estrutura de TI de igual complexidade e porte a lhe apoiar. A qualificação da instituição em pauta deve-se ao fato de se aproximar do modelo teórico proposto por Williamson (1991), e por não haver, até o momento, sido explorada essa necessária condição empírica.

A pesquisa foi realizada na empresa mãe e, em seguida, na empresa subsidiária. Por motivos de confidencialidade solicitados dos participantes, os nomes dos entrevistados e o nome do grupo estudado foram mantidos em sigilo. Essa foi a condição para a obtenção de informações do caso analisado, justificando a ocultação de tais informações.

Foram utilizados dados primários, conseguidos por meio de entrevistas semiestruturadas, com o objetivo de buscar evidências que pudessem ser associadas às cinco categorias (racionalidade limitada, frequência da transação, especificidade de ativos, incerteza e oportunismo) da TCT investigada neste estudo, e dados secundários coletados do site da empresa. As entrevistas foram realizadas em duas etapas: a primeira delas com três funcionários de nível estratégico da empresa subsidiária de Tl, e a segunda com dois funcionários de nível técnico operacional da empresa matriz. Após a realização das entrevistas, foi feita a sua transcrição, e os dados foram interpretados por meio do método da análise de conteúdo com o propósito de encontrar características que identificassem ou não a existência das categorias investigadas (BARDIN, 1995; BAUER; GASKELL, 2012). O caso envolvido e as análises dos dados coletados serão apresentados na próxima seção.

\section{APRESENTAÇÃO DO CASO E ANÁLISE DOS RESULTADOS}

A organização escolhida para este estudo de caso pauta-se em uma multinacional do ramo financeiro, que possui sede na Europa, com atuação global, e uma de suas subsidiárias de serviços de TI, localizada no Brasil. O foco dessa subsidiária está relacionado com o desenvolvimento de soluções de informática e prestação de serviços, como a exportação de tecnologia de ponta para países como Estados Unidos, México, Canadá, Inglaterra, Hong Kong e França. 
A sede brasileira amplia o desenvolvimento de soluções e ferramentas em mainframes, AS400, data warehousing, client server, databases, Unix, web development, e atua em praticamente todas as operações de TI que são necessárias para as empresas do grupo.

Por meio da coleta de dados feita com a empresa mãe e a empresa subsidiária, foram analisadas as cinco categorias da teoria custos de transação, abordados anteriormente no referencial teórico, para então identificar se a TCT é capaz de explicar a escolha da estratégia que o grupo financeiro fez ao manter uma estrutura de TI interna, em vez de usar a terceirização desse serviço, como feito em outras empresas.

Para a análise dos elementos da TCT, foram utilizados os termos "informante A" e "informante B", para a empresa mãe; e "informante X" e "informante Y", para a subsidiária, uma vez que foram feitas entrevistas nas duas estruturas.

\subsection{Oportunismo}

O oportunismo é um fator comportamental inerente aos agentes econômicos que buscam seus interesses próprios em detrimento do interesse do principal (WILLIAMSON, 1985). Esse pressuposto teórico não foi encontrado nas entrevistas realizadas em ambas as organizações, o que pode ser notado na seguinte citação: "não considero a existência de ações oportunistas, pois a maioria dos funcionários (da empresa subsidiária) é altamente comprometida com a organização" (funcionário B). Cabe ressaltar que o oportunismo não foi identificado por meio das entrevistas feitas com os funcionários da empresa mãe talvez pelo fato de a estrutura de TI ser interna. De acordo com os pressupostos da TCT, quando são realizadas transações de mercado - ao comprar serviços de TI, por exemplo -, as transações estariam sob influência do oportunismo.

\subsection{Racionalidade limitada}

Conforme argumentado por Simon (1965), o ser humano não é capaz de tomar decisões ótimas, mas sim satisfatórias. Na pesquisa de campo, evidenciou-se a ocorrência de falhas de comunicação, como uma das fontes para as decisões erradas, entre a empresa subsidiária e a empresa mãe, o que dificulta a interpretação das necessidades da empresa mãe pela subsidiária. Tal fato pode ser identificado no seguinte trecho: "sob meu ponto de vista, os problemas que possam levar à conclusão contrária são, com raras exceções, as falhas na comunicação entre business e TI" (funcionário A). Embora esse fato tenha sido constatado na empresa mãe, o funcionário $X$ da empresa subsidiária alegou que não há falhas de comunicação que justifiquem erros. No entanto, como a racionalidade limitada, no contexto apresentado por Simon (1965) e assumido por Williamson (1991), é um fator inerente a todos os seres humanos, pode-se dizer que a presença da racionalidade limitada no caso analisado não foi questão preponderante para a estratégia de manutenção da TI interna. Esse fator teria forte influência na questão dos custos de transação caso fosse necessário o estabelecimento de um contrato entre a empresa, que necessita de serviços, e outra organização responsável pela execução do serviço de Tl, por meio da governança de mercado. Logo, esse contrato não seria capaz de abranger todos os problemas possíveis de acontecer, aumentando possivelmente os custos de transação.

\subsection{Frequência da transação}

Conforme Williamson (1985), quanto maior a frequência da transação, maiores são as chances de os custos de transação aumentarem. De acordo com o funcionário $B$, a empresa subsidiária deve cobrir doze horas de suporte de sistemas para todas as unidades da empresa mãe no mundo. Ele também explicou que a opção pela construção de uma unidade de TI no Brasil deu-se pelo fuso horário diferente dos outros centros de TI pertencentes ao grupo financeiro multinacional. Dessa forma, ao final do expediente de um centro de TI, uma equipe de outro país já se encontra em atividade, com o objetivo de oferecer o suporte 24 horas por dia. Portanto, há uma alta frequência de transação, o que, de acordo com a teoria, leva uma empresa a preferir a estratégia de governança hierárquica. 


\subsection{Incerteza}

A incerteza é descrita por Silva e Brito (2013) como a imprevisibilidade de mudanças e a dissimilaridade dos elementos ambientais. Esse constructo foi identificado na pesquisa de campo principalmente pelos conflitos de agência que poderiam ocorrer entre o agente (no caso, a empresa terceirizada) e o principal (a empresa contratante dos serviços de $\mathrm{TI}$ ) caso a TI do grupo financeiro multinacional fosse terceirizada. Tanto os funcionários da empresa subsidiária quanto os da principal alegaram que a TI era importante demais para as atividades essenciais do grupo e, por isso, não deveria ser terceirizada. Como há a necessidade de suporte 24 horas por dia para as diversas unidades da empresa principal, a TI terceirizada poderia representar algumas incertezas para o grupo quanto a sua disponibilidade, e empenho na resolução dos diversos problemas que poderiam acontecer.

\subsection{Especificidade de ativos}

Ativos específicos são caracterizados por investimentos que não podem ser reempregados sem sacrifício do seu valor produtivo (WILLIAMSON, 1991), ou seja, são ativos com alto grau de especificidade e detalhamento que não podem ser facilmente utilizados para outros fins.

Pearlson e Saunders (2010, p. 49) explicam que "um ativo de TI é qualquer coisa, tangível ou intangível, que pode ser usada por uma empresa em seus processos de criação, produção e/ou para oferecer seus produtos (bens ou serviços)", ao passo que, ao mesmo tempo, pode ser relacionado aos recursos humanos, à base tecnológica utilizada, bem como à associação entre a gestão de TI e o negócio desempenhado (LAURINDO et al., 2001).

Nesse aspecto, os ativos específicos relacionam-se ao modo como uma empresa usa seus ativos de $\mathrm{TI}$ de forma eficaz, quer dizer, em como utiliza sua capacidade de TI ao longo do tempo, por meio da criação, produção, fornecimento e gestão de seus produtos ou serviços, considerando suas habilidades técnicas (concepção, desenvolvimento e implementação da informação), de gerenciamento (gestão de projetos de TI) e de relacionamento (interno e externo) (PEARLSON; SAUNDERS, 2010).

Diante das referências teóricas sobre a especificidade de ativos, pode-se dizer que, no caso analisado, a TI torna-se um ativo com elevado grau de especificidade e detalhamento. Essa constatação pode ser observada no seguinte trecho da entrevista: "há muitas atividades e decisões estratégicas que sugerem grande nível de confidencialidade e segurança da informação, estes casos são muito importantes para serem deixados sob controle de empresas terceirizadas" (funcionário A).

Com base nas cinco dimensões aqui consideradas, desenvolveu-se o Quadro 1, que apresenta um resumo a respeito da análise feita, sob o ponto de vista da TCT, no caso da empresa mãe e de sua subsidiária de TI. 
Quadro 1 - Resumo da análise dos dados

\begin{tabular}{|c|c|c|c|c|c|}
\hline & \multicolumn{2}{|c|}{ Pressupostos comportamentais } & \multicolumn{3}{|c|}{ Características das transações } \\
\hline & Oportunismo & $\begin{array}{l}\text { Racionalidade } \\
\text { limitada }\end{array}$ & $\begin{array}{l}\text { Frequência da } \\
\text { transação }\end{array}$ & Incerteza & $\begin{array}{l}\text { Especificidade } \\
\text { de ativos }\end{array}$ \\
\hline $\begin{array}{l}\text { Explicação } \\
\text { de acordo } \\
\text { com a teoria }\end{array}$ & $\begin{array}{c}\text { Em estratégias } \\
\text { de governança } \\
\text { de mercado, } \\
\text { como a } \\
\text { terceirização, } \\
\text { as relações } \\
\text { contratuais } \\
\text { estão sujeitas } \\
\text { a ações } \\
\text { oportunistas } \\
\text { executadas } \\
\text { pelos agentes. }\end{array}$ & $\begin{array}{l}\text { Em estratégias de } \\
\text { governança de } \\
\text { mercado, como } \\
\text { a terceirização, } \\
\text { os contratos } \\
\text { não conseguem } \\
\text { abranger todos } \\
\text { os problemas } \\
\text { que poderiam } \\
\text { acontecer. Isso } \\
\text { ocorre pela } \\
\text { influência da } \\
\text { racionalidade } \\
\text { limitada. }\end{array}$ & $\begin{array}{l}\text { Quanto maior } \\
\text { a frequência da } \\
\text { transação, maior } \\
\text { a tendência para } \\
\text { a integração } \\
\text { (governança } \\
\text { hierárquica). }\end{array}$ & $\begin{array}{l}\text { Quanto mais } \\
\text { incerto for } \\
\text { o ambiente, } \\
\text { maior a } \\
\text { tendência para } \\
\text { a governança } \\
\text { hierárquica. }\end{array}$ & $\begin{array}{l}\text { Quanto mais } \\
\text { específico } \\
\text { o ativo } \\
\text { envolvido, maior } \\
\text { a tendência } \\
\text { para a } \\
\text { governança } \\
\text { hierárquica. }\end{array}$ \\
\hline $\begin{array}{c}\text { Resultados } \\
\text { encontrados } \\
\text { pela } \\
\text { pesquisa }\end{array}$ & $\begin{array}{c}\text { Esse elemento } \\
\text { não foi } \\
\text { encontrado } \\
\text { na pesquisa, } \\
\text { uma vez que a } \\
\text { TI foi mantida } \\
\text { internamente. }\end{array}$ & $\begin{array}{l}\text { Fator que exerce } \\
\text { influência } \\
\text { principalmente } \\
\text { na construção } \\
\text { de contrato, em } \\
\text { que nem todas } \\
\text { as possibilidades } \\
\text { são contempladas. } \\
\text { Nesse caso, como } \\
\text { os serviços de TI } \\
\text { são feitos por meio } \\
\text { da governança } \\
\text { hierárquica, não } \\
\text { são necessários } \\
\text { contratos. }\end{array}$ & $\begin{array}{l}\text { Os serviços } \\
\text { de TI são } \\
\text { utilizados com } \\
\text { alta frequência } \\
\text { pelo grupo } \\
\text { financeiro. }\end{array}$ & $\begin{array}{c}\text { A pesquisa } \\
\text { identificou que } \\
\text { os serviços } \\
\text { de TI são } \\
\text { importantes } \\
\text { para a } \\
\text { empresa } \\
\text { analisada; } \\
\text { portanto, } \\
\text { terceirizá-los } \\
\text { seria depender } \\
\text { de outra } \\
\text { empresa, } \\
\text { aumentando } \\
\text { a incerteza do } \\
\text { negócio. }\end{array}$ & $\begin{array}{l}\text { Conforme a } \\
\text { pesquisa feita, } \\
\text { os serviços de } \\
\text { TI são de alta } \\
\text { especificidade, } \\
\text { sendo seus } \\
\text { usos feitos } \\
\text { exclusivamente } \\
\text { pela empresa } \\
\text { mãe. Dessa } \\
\text { forma, terceirizar } \\
\text { esse tipo de } \\
\text { serviço poderia } \\
\text { acarretar vários } \\
\text { problemas, } \\
\text { como a falta de } \\
\text { customização, } \\
\text { conforme } \\
\text { apontado pelos } \\
\text { informantes. }\end{array}$ \\
\hline
\end{tabular}

Fonte: Os autores (2015)

Como demonstrado no Quadro 1, os fatores comportamentais, inerentes a todos os seres humanos, dentro da explicação da TCT, não foram encontrados, no caso analisado, como influenciadores para o aumento dos custos de transação. Isso, possivelmente, ocorreu em razão de sua escolha estratégica. Caso a empresa optasse por suprir sua demanda por intermédio do mercado, comprando serviços de TI de empresas especializadas, seriam necessários contratos que dificilmente abrangeriam todos os possíveis acontecimentos em razão da racionalidade limitada. Além desse fator, se a empresa escolhesse a governança de mercado, as relações entre a agência (no caso, a empresa mãe) e o agente (a empresa terceirizada) estariam sujeitas a ações oportunistas do agente que, ao defender seus interesses, poderiam afetar negativamente a empresa contratante.

Já as características das transações foram observadas mais nitidamente no campo de estudo deste artigo. A frequência da utilização dos serviços de TI mostrou-se alta entre a empresa mãe e a subsidiária. Portanto, muitos problemas poderiam acontecer se a opção feita fosse por uma empresa terceirizada e não por uma estrutura interna de TI.

No que diz respeito à incerteza, cabe esclarecer que o ativo envolvido no caso analisado são os serviços de TI que servem para a empresa mãe para o processamento de dados, tanto da empresa, quanto de seus clientes. Em virtude disso, como apontado pelos entrevistados, seria arriscado deixar essas informações sob o controle de outra empresa. Como as informações da própria organização e de seus clientes são altamente sigilosas, colocá-las sob o poder de terceiros poderia aumentar a incerteza quanto à sua manutenção e 
confidencialidade. Por conseguinte, a manutenção de uma subsidiária de TI foi uma alternativa encontrada pelo grupo para diminuir as dúvidas da forma de governança de mercado.

No que concerne à especificidade de ativos, último elemento analisado, é importante ressaltar que o processamento de dados para uma empresa que tem esse ativo como fundamental para a execução de seu negócio global é algo muito específico e condicioná-lo ao trabalho de uma empresa terceirizada poderia resultar em problemas, como a demora em ajustes de sistema, processamento de relatórios, dentre outros.

Embora importantes, questões como o percentual de redução de custos e aumento de produtividade, relacionadas às contribuições quantificáveis da estratégia de manutenção de uma estrutura interna de TI pela empresa mãe não foram tratadas nesta pesquisa. A justificativa para isso foi a recusa dos entrevistados quando perguntados a propósito dos impactos quantificáveis da estrutura interna de TI. Além disso, este estudo é de cunho qualitativo; consequentemente, "relações causa e efeito", e contribuições quantificáveis assumem menor importância, quando comparadas ao entendimento do fenômeno em profundidade, alvo desta pesquisa.

\section{CONSIDERAÇÕES FINAIS}

A tecnologia da informação pode ser considerada um fator que auxilia as organizações a se tornarem e a se manterem mais competitivas no mercado (ALBERTIN; ALBERTIN, 2005). No entanto, algumas decisões devem ser tomadas para que a TI traga os benefícios esperados para o negócio. Uma dessas decisões refere-se à estratégia de governança da organização no que concerne a terceirizar seus serviços de TI (governança de mercado) ou a manter uma estrutura interna para essas atividades (governança hierárquica).

Diante dessas decisões estratégicas, foi delineado o objetivo deste texto em analisar como uma subsidiária de TI pode contribuir para a economia dos custos de transação de um grupo financeiro multinacional. Com base nas evidências encontradas na pesquisa de campo, analisadas e discutidas aqui, nota-se que o alinhamento da estratégia de Tl que melhor se adapta à realidade e posicionamento estratégico da empresa também pode incidir em suas transações, à medida que tais custos são somados aos seus custos operacionais (custos aparentes do produto ou serviço).

No caso mencionado, a empresa mãe optou por instituir uma subsidiária de TI pertencente ao próprio grupo. A escolha por tal estratégia, como salientam Birkinshaw e Morrison (1995), Birkinshaw e Hood (1998), pode ter ocorrido por causa da capacidade de centralização de informações, para desenvolver competências para inovar ou mesmo para obter customização nos serviços realizados, conforme observado também no estudo de campo. Tais elementos considerados importantes para a empresa dificilmente seriam alcançados com uma estrutura de TI externa, em virtude dos vários elementos que poderiam elevar os custos de transação, mencionados anteriormente.

Logo, a estratégia de TI utilizada pela empresa estudada condiz com as indicações feitas pela TCT, pois, ao adotar uma estratégia de governança hierárquica (WILLIAMSON, 1979), por meio da adoção de TI interna, a empresa em questão não fica sujeita aos custos de transação que poderiam existir na relação da empresa demandante de serviços de TI e uma empresa especializada na atividade.

Nesse sentido, pode-se dizer que o fato de o grupo multinacional ter optado por uma subsidiária de TI pode ter sido em virtude da diminuição dos seus custos de transação. Mesmo diante dos vários fatores que incentivam as empresas a adotarem TI terceirizada, descritos no referencial teórico deste artigo, sendo o principal deles o baixo custo, a empresa decidiu pela governança hierárquica.

Assim, tais evidências apontadas na pesquisa de campo possibilitam compreender que o grupo multinacional utilizou a estratégia de manter a TI sob a forma de governança hierárquica por causa do ambiente de incertezas, pela característica de ativo específico relacionado aos serviços em questão, bem como pela frequência das transações e pelos fatores comportamentais que poderiam aumentar ainda mais os custos totais, ao influenciar nos custos de transação.

Por fim, com a finalidade de ampliar a compreensão acerca do fenômeno estudado, sugere-se a realização de estudo quantitativo a fim de que se possa verificar a relação entre os cinco elementos da TCT e para que seja possível obter uma análise longitudinal das opções estratégicas entre as diferentes formas de governança. Pode-se igualmente sugerir um estudo qualitativo, realizado em uma organização com estratégia de TI semelhante à discutida aqui, com o propósito de comparar os resultados encontrados. 


\title{
IT SUBSIDIARY AS STRATEGIC ALTERNATIVE FOR TRANSACTION COST ECONOMICS
}

\begin{abstract}
This article aims to analyze how an IT subsidiary can contribute to the economy of transaction costs of a multinational financial group. To better understand these relationships and identify whether there are savings in transaction costs, a case study was conducted. Its purpose was to seek evidence of the five dimensions of the theory of transaction costs: opportunism, bounded rationality, uncertainty, asset specificity and transaction frequency. The data used for the study was obtained by means of documentary and bibliographical research and interviews with employees from both organizations involved. The results of this study demonstrate that the capacity of centralization of information, so as to develop skills to innovate or the customization of the services provided by the parent company, was one of the factors that led to the maintenance of their own IT structure . In addition, due to behavioral assumptions, the characteristics of the transactions and the assets involved, maintaining an integrated IT structure in the hierarchical dimension in the form of a subsidiary, can guarantee savings in transaction costs for the main organization. The results confirm the principles of the Theory of Transaction Costs.
\end{abstract}

Keywords: Multinational Financial Group. IT Subsidiary. Transaction Cost Economics.

\section{REFERÊNCIAS}

ALBERTIN, R. M. M; ALBERTIN, A. L. Benefício do Uso da Tecnologia de Informação no Desempenho Empresarial. In: ALBERTIN, A. L.; ALBERTIN, R. M. M. Tecnologia da Informação: desafios da tecnologia de informação aplicada aos negócios. São Paulo: Atlas, 2005. cap. 3.

BARDIN, Laurence. Análise de conteúdo. Lisboa: Editora 70, 1995.

BAUER, M. W.; GASKELL, G. Pesquisa qualitativa com texto, imagem e som: um manual prático. 10. ed. Petrópolis, RJ: Vozes, 2012.

BRAND FINANCE. The most valuable banking brands of 2015. Disponível em: $<$ http://brandirectory.com/ league_tables/table/banking-500-2015>. Acesso em: 30 abr. 2015.

BIRKINSHAW, J.; HOOD, N. Multinational subsidiary evolution: capability and charter change in foreign-owned subsidiary companies. Academy of Management Review, New York, v. 23, n. 4, p. 773-795, 1998.

BIRKINSHAW, J.; MORRISON, A. Configurations of strategy and structure in subsidiaries of multinational corporations. Journal of International Business Studies, East Lansing, MI, v. 26, n. 4, p. 729-754, 1995.

CARSON, S. J.; MADHOK, A.; WU, T. Uncertainty, opportunism, and governance: the effects of volatility and ambiguity on formal and relational contracting. Academy of Management Journal, New York, v. 49, n. 5, p. 1058-1077, 2006.

CERVO, A. L.; BERVIAN, P. A. Metodologia científica. 5. ed. São Paulo: Pearson Prentice Hall, 2002.

CLARK, G. L.; MONK, A. H. B. The scope of financial institutions: in-sourcing, outsourcing and off-shoring. Journal of Economic Geography, Oxford, v. 3, n. 2, p. 279-298, 2013.

COASE, R. H. The nature of the firm. Econômica, Niterói, v. 4, n. 16, p. 386-405, 1937.

CORDENONSI, J. L. Alinhamento das estratégias de TI e de negócio: As melhores práticas utilizadas pelos Bancos privados Brasileiros. In: ABERTIN, A. L; ALBERTIN, R. M. M. Tecnologia da Informação: desafios da tecnologia de informação aplicada aos negócios. São Paulo: Atlas, 2005. cap. 7.

DEQUECH, D. Bounded rationality, institutions and uncertainly. Journal of Economics, Vienna, Austria, v. 35, n. 4, p. 911-929, 2001. 
DENZIN, N. K; LINCOLN, Y. S. O planejamento da pesquisa qualitativa: teorias e abordagens. 2. ed. Porto Alegre: Artmed, 2006.

LAURINDO, F. J. B. et al. O papel da Tecnologia da Informação (TI) na estratégia das organizações. Gestão \& Produção, São Carlos, v. 8, n. 2, p. 160-179, 2001.

LUCAS, H. C. Tecnologia da informação: tomada de decisão estratégica para administradores. Rio de Janeiro: LTC, 2006.

LUO, Y. Toward coopetition within a multinational enterprise: a perspective from foreign subsidiaries. Journal of World Business, Pennsylvania, USA, v. 40, p. 71-90, 2005.

MESQUITA, D. L. et al. O desenvolvimento de processos de inovação sob a ótica da teoria dos custos de transação: o caso da tecnologia flex-fuel. Revista de Administração e Inovação, São Paulo, v. 10, n. 1, p. 119140, 2013.

PEARLSON, K. E.; SAUNDERS, C. S. Managing and using information systems: A strategic approach. 4. ed. United States of America: John Wiley \& Sons, Inc., 2010.

PRADO, E. P. V.; TAKAOKA, H. Os fatores que motivam a adoção da terceirização da tecnologia de informação: uma análise do setor industrial de São Paulo. Revista de Administração Contemporânea, Rio de Janeiro, v. 6, n. 3, p. 129-147, 2002.

RODRIGUES, L. C.; MACCARI, E. A.; SIMÕES, S. A. O desenho da gestão da Tecnologia da Informação nas 100 maiores empresas na visão dos executivos de TI. Revista de Gestão da Tecnologia e Sistemas de Informação, São Paulo, v. 6, n. 3, p. 483-506, 2009.

SCUMPARIM, D.; SACOMANO NETO, M. Recursos, controle e autonomia na gestão internacional de serviços de uma empresa de ti e subsidiárias. RAE - Revista de Administração de Empresas, São Paulo, v. 52, n. 4, p. 407-420, 2012.

SILVA, M. A. da et al. Outsourcing de Ti e Redefinição do Papel da Subsidiária: Um Estudo Comparativo entre as Subsidiárias Brasileira e Indiana de uma Multinacional Americana. Revista de Gestão da Tecnologia e Sistemas de Informação, São Paulo, v. 6, n. 2, p. 173-202, 2009.

SILVA, A. A.; BRITO, E. P. Z. Incerteza, racionalidade limitada e comportamento oportunista: um estudo na indústria brasileira. RAM, Rev. Adm. Mackenzie, São Paulo, v. 14, n. 1, p. 176-201, 2013.

SIMON, H. Comportamento Administrativo. São Paulo: FGV, 1965.

TAGGART, J. H. Autonomy and Procedural Justice: A Framework For Evaluating Subsidiary Strategy. Journal of International Business Studies, Copenhagen, Denmark, v. 28, n. 1, p. 51-76, 1997.

WILLIAMSON, O. E. Markets and Hierarchies: analysis and antitrust implications. Free Press: New York, 1975. WILLIAMSON, O. E. Transaction-cost economics: the governance of contractual relations. Journal of law and economics, Chicago, v. 22, n. 2, p. 233-261, 1979.

WILLIAMSON, O. E. The economics of organization: the transaction cost approach. American Journal of Sociology, Chicago, p. 548-577, 1981.

WILLIAMSON, O. E. The economic institutions of capitalism: Firms, markets, relational contracting. New York: Free Press, 1985.

WILLIAMSON, O. E. Strategizing, economizing, and economic organization. Strategic Management Journal, Indiana, USA, v. 12, n. S2, p. 75-94, 1991.

YIN, R. K. Estudo de caso: planejamento e métodos. 3. ed. Porto Alegre: Bookman, 2005. 